\title{
Linear Copolymers Based on Choline Ionic Liquid Carrying Anti-Tuberculosis Drugs: Influence of Anion Type on Physicochemical Properties and Drug Release
}

\author{
Katarzyna Niesyto and Dorota Neugebauer *(D)
}

Citation: Niesyto, K.; Neugebauer, D. Linear Copolymers Based on Choline Ionic Liquid Carrying Anti-Tuberculosis Drugs: Influence of Anion Type on Physicochemical Properties and Drug Release. Int. J. Mol. Sci. 2021, 22, 284. https://doi.org/10.3390/ijms22010284

Received: 13 December 2020 Accepted: 27 December 2020 Published: 30 December 2020

Publisher's Note: MDPI stays neutral with regard to jurisdictional clai$\mathrm{ms}$ in published maps and institutional affiliations.

Copyright: (C) 2020 by the authors. Licensee MDPI, Basel, Switzerland. This article is an open access article distributed under the terms and conditions of the Creative Commons Attribution (CC BY) license (https:// creativecommons.org/licenses/by/ $4.0 /)$.
Department of Physical Chemistry and Technology of Polymers, Faculty of Chemistry, Silesian University of Technology, 44-100 Gliwice, Poland; Katarzyna.Niesyto@polsl.pl * Correspondence: Dorota.Neugebauer@polsl.pl

\begin{abstract}
In this study, drug nanocarriers were designed using linear copolymers with different contents of cholinium-based ionic liquid units, i.e., [2-(methacryloyloxy)ethyl]trimethylammonium chloride (TMAMA/Cl: 25, 50, and $75 \mathrm{~mol} \%$ ). The amphiphilicity of the copolymers was evaluated on the basis of their critical micelle concentration $(\mathrm{CMC}=0.055-0.079 \mathrm{mg} / \mathrm{mL}$ ), and their hydrophilicities were determined by water contact angles $\left(\mathrm{WCA}=17^{\circ}-46^{\circ}\right)$. The chloride anions in the polymer chain were involved in ionic exchange reactions to introduce pharmaceutical anions, i.e., p-aminosalicylate $\left(\mathrm{PAS}^{-}\right)$, clavulanate $\left(\mathrm{CLV}^{-}\right)$, piperacillin $\left(\mathrm{PIP}^{-}\right)$, and fusidate $\left(\mathrm{FUS}^{-}\right)$, which are established antibacterial agents for treating lung and respiratory diseases. The exchange reaction efficiency decreased in the following order: $\mathrm{CLV}^{-}>\mathrm{PAS}^{-}>\mathrm{PIP}^{-}>\mathrm{FUS}^{-}$. The hydrophilicity of the ionic drug conjugates was slightly reduced, as indicated by the increased WCA values. The major fraction of particles with sizes $\sim 20 \mathrm{~nm}$ was detected in systems with at least 50\% TMAMA carrying PAS or PIP. The influence of the drug character and carrier structure was also observed in the kinetic profiles of the release processes driven by the exchange with phosphate anions $(0.5-6.4 \mu \mathrm{g} / \mathrm{mL})$. The obtained polymer-drug ionic conjugates (especially that with PAS) are promising carriers with potential medical applications.
\end{abstract}

Keywords: choline; anion exchange; antibacterial activity; polymer carriers

\section{Introduction}

Polymer-based drug delivery systems (DDS) are of great interest to the scientific community because of their various advantages. These vehicles improve the pharmacokinetics and pharmacodynamics involved in transporting the drug to the destination of therapeutic action [1-4]. Therefore, the most requested systems are the targeted and controlled DDS [5-8]. The delivery properties can be adjusted by modifying the polymer structure to avoid the uncontrolled rate of drug release [9-11]. Drug release can also be activated by specific conditions that are characteristic of unhealthy cells, i.e., $\mathrm{pH}$, temperature, or ionic strength [12-15]. The responsiveness of polymer vehicles to $\mathrm{pH}$ changes are commonly used in the treatment of cancer cells due to their acidic reaction, which is an opposite to alkaline environment in healthy cells [16]. Additionally, the unhealthy cells usually gain higher temperature, which is exploited by temperature-responsive polymer carriers for specific behavior in the conditions of their lower or upper critical solution temperature [17]. Mechanisms based on ionic strength are characteristic for polymers containing ionic groups. Ion exchange controlled release systems are applied in delivery of ionic drugs, which can be attached to polymer matrix by ionic interactions. The ion delivery depends on the type and geometry of ionic carrier, charge intensity, and coordination number of ionic groups, as well as ionic strength of polymer solution [18].

Diverse types of carrier are known, some of them are polymer-drug conjugates, in which the latter component is connected directly to the polymeric matrix by a chemical 
bond or through the linker $[19,20]$. If the conjugate has amphiphilic properties, the drug can be encapsulated inside the self-assembled structure [21], thus constituting dual drug codelivery systems, which have also been applied in combined therapies [22,23]. Compared with traditional drugs, the presence of a polymer carrier is intended to ensure the solubility of the hydrophobic drug in aqueous solution, which is desirable to optimize the drug's effect on the human body $[24,25]$. Conjugate design requires individualized strategies that involve introducing the appropriate type of connection between the drug and the polymeric matrix to achieve the desired release profile $[26,27]$.

Ionic liquids (ILs), which are popular in various fields of chemistry, are also convenient for drug delivery because of their ionic nature and ion exchange capabilities, which are useful to tune biochemical properties and to generate pharmaceutical activity. As a result, the drug (in an anionic or cationic form) can be introduced into polymer matrix, wherein it is ionically bonded with a counterion [28]. Choline ((2-hydroxyethyl)trimethylammonium chloride), as an IL with vitamin-like functions, is a known carrier of anti-inflammatory salicylates and can be applied as a biological cation owing to its biocompatibility and antibacterial properties [29-31]. Moreover, this molecule and its phosphoryl derivative are capable of degradation under anaerobic conditions [32,33]. The (phosphoryl)choline in a methacrylatefunctionalized form has been polymerized to obtain a biocompatible poly(ionic liquid) (PIL) for pharmacological and medical applications. For example, poly(2-methacryloyloxyethyl) phosphorylcholine has been reported as a suitable component of implants, medical devices, or DDS [34-36]. Similarly, poly[2-(methacryloyloxy)ethyl]trimethylammonium chloride (PTMAMA) has demonstrated bactericidal and fungicidal properties [37]. Moreover, its high hydrophilicity can be modified by incorporating hydrophobic units into the polymer chain or by exchanging with hydrophobic anions to yield the amphiphilic copolymer [38], which can create micellar systems in aqueous solution and consequently enable encapsulation of non-ionic drugs [39]. On the other hand, the combination of quaternary ammonium cations with chloride counter ions has been convenient for anion exchange reactions to introduce the ionic drug [40], thus forming the ionic type of polymer-drug conjugates. These systems comprised the graft topology of PTMAMA carrying the pharmaceutical anions, such as salicylate [41], $p$-aminosalicylate, or clavulanate [42]. In these cases, the drug release occurred in the solution containing the stronger ions (i.e., phosphate ions), which is in contrast to conventional conjugates, where the drug is released by hydrolytic degradation of a linker (usually ester- or amide-type). Other PIL-based DDSs have been reported for poly(imidazolium salt)s carrying naproxen anions [43] or poly(guanidinium salt)s with antibiotic anions [44].

In the present work, we describe linear PILs based on [2-(methacryloyloxy)ethyl] trimethylammonium chloride (TMAMA) as the universal matrix for potential polymerdrug ionic conjugates. These copolymers with varied ionic group contents were synthesized via controlled polymerization reaction (i.e., atom transfer radical polymerization (ATRP)). New drug delivery systems were designed by employing the anion exchange reaction with selected drugs in ionic form, such as $p$-aminosalicylic $\left(\mathrm{PAS}^{-}\right)$, clavulanic $\left(\mathrm{CLV}^{-}\right)$, fusidic ( $\mathrm{FUS}^{-}$), and piperacillin ( $\mathrm{PIP}^{-}$) anions as the antibacterial agents. $p$-Aminosalicylic acid has antitubercular activity, which extinguishes the growth and multiplication of Mycobacterium tuberculosis, leading to cell apoptosis, so it is predominantly used to support the action of other anti-tuberculosis drugs. Clavulanic acid isolated from Streptomyces is a weak antimicrobial agent and $\beta$-lactamase inhibitor that precludes deactivation of antibiotic in combination therapy for bacterial infections (i.e., acute bronchitis and upper respiratory tract infections). Piperacillin acid as an ampicillin-derived antibiotic with broad-spectrum bactericidal activity, and it is clinically efficient in the treatment of infections caused by Streptococcus pneumoniae, including lung diseases. Fusidic acid is a natural steroid antibiotic that shows bacteriostatic activity without the corticosteroid effects, and it is effective against Bordetella pertussis and Staphylococcus aureus, which damage the respiratory system. The aforementioned drugs are typically administrated orally during conventional treatments. The influence of the carrier composition and the anion type on the physicochemical proper- 
ties, exchange effect, and progress of pharmaceutics release are investigated in this work, in order to inform the design single-drug delivery systems with potential for the treatment of lung and respiratory diseases. Previously, $\mathrm{PAS}^{-}$and $\mathrm{CLV}^{-}$based systems have been studied in combination with PTMAMA graft copolymers [42]. However, in those cases the TMAMA units were located in the side chains, which were formed by grafting from polymethacrylate macroinitiator. Similarly to linear copolymers they were varied with content of ionic units, but in the grafted ones this range was narrower (13-46\%), and the TMAMA copolymer side chains were significantly shorter (16-65 repeating units). Fundamental difference was the grafting degree ( $25 \%$ and $50 \%$ ) defining the distribution density of side chains attached to the hydrophobic backbone. Thus, the linear TMAMA copolymers were investigated to evaluate their delivery potential in comparison to analogous ionic carriers with graft topology.

\section{Results and Discussion}

Several carriers were designed with statistically distributed ionic units, which act as polymer-drug conjugates. To obtain such systems, PILs containing an ionic monomer (i.e., TMAMA/Cl as M1) in combination with methyl methacrylate (MMA as M2) as a comonomer were copolymerized in different ratios (C1: 25/75, C2: 50/50, and C3: 75/25) by ATRP at $40{ }^{\circ} \mathrm{C}$. The reaction was initiated by ethyl 2-bromoisobutyrate (EBiB) and catalyzed by a copper bromide $/ N, N, N^{\prime}, N^{\prime \prime}, N^{\prime \prime}$-pentamethyldiethylenetriamine (CuBr/PMDETA) complex. As a result, linear copolymers were prepared with varying content of ionic units, which corresponded to the initial proportion of TMAMA/MMA in the reaction mixture (Figure 1, Table 1). In our previous studies on the copolymerization of TMAMA and MMA formation of statistical copolymers was postulated due to comparable relative reactivity ratios of comonomers, that is $\mathrm{r}_{\mathrm{TMAMA} / \mathrm{Cl}}=1.13$ and $\mathrm{r}_{\mathrm{MMA}}=0.88$ [38].

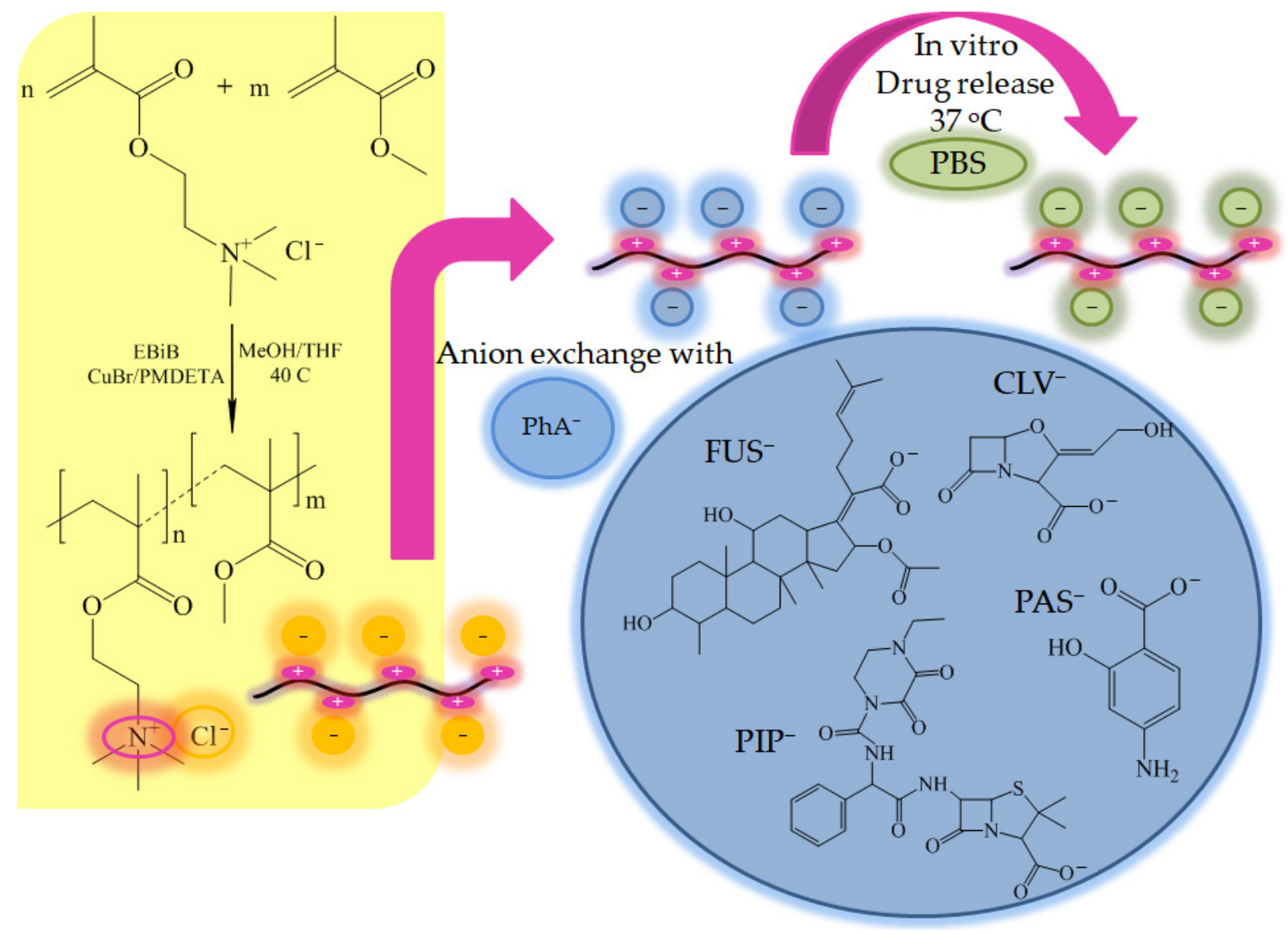

Figure 1. Schematic anion exchange pathway for obtaining linear TMAMA-based copolymers. 
Table 1. Characteristics of linear copolymers based on choline ionic liquid (IL) synthetized by atom transfer radical polymerization (ATRP).

\begin{tabular}{|c|c|c|c|c|c|c|c|c|c|}
\hline \multirow[b]{2}{*}{ No. } & \multirow[b]{2}{*}{ M1/M2 } & \multicolumn{6}{|c|}{${ }^{1} \mathrm{H}_{\mathrm{NMR}}{ }^{\mathrm{a}}$} & \multicolumn{2}{|c|}{ SEC $^{b}$} \\
\hline & & $\begin{array}{l}X_{\mathrm{M} 1} \\
(\%)\end{array}$ & $\begin{array}{c}X_{M 2} \\
(\%)\end{array}$ & $\mathrm{DP}_{\mathrm{M} 1}$ & $\mathrm{DP}_{\mathrm{n}}$ & $\begin{array}{l}F_{M 1} \\
(\%)\end{array}$ & $\begin{array}{c}\mathrm{M}_{\mathrm{n}} \times 10^{3} \\
(\mathrm{~g} / \mathrm{mol})\end{array}$ & $\begin{array}{c}\mathrm{M}_{\mathrm{n}} \times 10^{3} \\
(\mathrm{~g} / \mathrm{mol})\end{array}$ & Đ \\
\hline $\mathrm{C} 1$ & $25 / 75$ & 59.8 & 62.3 & 90 & 370 & 24 & 46.9 & 5.7 & 1.74 \\
\hline $\mathrm{C} 2$ & $50 / 50$ & 78.6 & 80.5 & 236 & 477 & 49 & 73.3 & 11.9 & 1.36 \\
\hline $\mathrm{C} 3$ & $75 / 25$ & 88.1 & 86.6 & 396 & 526 & 75 & 95.5 & 16.7 & 1.27 \\
\hline
\end{tabular}

M1: TMAMA/Cl, M2: MMA; conditions: C1: [M1+M2 $]_{0}:[\mathrm{EBiB}]_{0}:[\mathrm{CuBr}]_{0}:[\mathrm{PMDETA}]_{0}=600: 1: 1: 1,24 \mathrm{~h}$ methanol:THF $=3: 1 v / v$, where methanol:M1 $=1: 1 v / w t ., 40^{\circ} \mathrm{C} ; \mathrm{X}_{\mathrm{M} 1}$ and $\mathrm{X}_{\mathrm{M} 2}$ are conversions of TMAMA/Cl and MMA, respectively; $\mathrm{DP}_{\mathrm{M} 1}$ is polymerization degree of TMAMA/Cl units; $\mathrm{DP}_{\mathrm{n}}$ is polymerization degree; $\mathrm{F}_{\mathrm{M} 1}$ is content of TMAMA/Cl fraction in the polymer. ${ }^{\text {a }}$ deuterated dimethyl sulfoxide (DMSO- $\left.\mathrm{d}_{6}\right)$, tetramethylsilane (TMS) internal standard; ${ }^{b}$ tetrahydrofuran (THF) solvent, polystyrene calibration.

The use of methanol as co-solvent in the reaction mixture can be disadvantageous because of possible transesterification of TMAMA/Cl to MMA as side reaction during polymerization $[45,46]$. Our previous studies showed that it can be minimized effectively at reduced amount of methanol ( $1 \mathrm{~mL}$ per $1 \mathrm{~g}$ of TMAMA) and at higher initial content of TMAMA ( $\geq 25 \%$ ) [38]. Thus the use of optimized conditions of copolymerization, i.e., ratios of TMAMA/MMA (25/75, 50/50, 75/25), and low amount of methanol in the reaction mixture ( $1 \mathrm{~mL}$ per $1 \mathrm{~g}$ of TMAMA), allowed excluding transesterification, which was confirmed by the calculated content of ionic fraction $\left(\mathrm{F}_{\mathrm{MI}}\right)$ in the copolymer (it was different from that initial by $1 \%$ ).

The copolymer structure was confirmed by proton nuclear magnetic resonance $\left({ }^{1} \mathrm{H}\right.$ NMR) spectroscopy, which revealed proton signals from methyl groups at 1.4-0.6 ppm and methylene groups at 2.0-1.6 ppm in the main chain (Figure 2). Additionally, signals from methoxy protons at 3.7-3.5 ppm in MMA units, and from oxyethylene and methyl groups in the ammonium cation of TMAMA/Cl units $(4 \mathrm{H}$ at $4.6-4.1 \mathrm{ppm}$ and $9 \mathrm{H}$ groups at 3.4 and $3.3 \mathrm{ppm}$, respectively) confirmed the incorporation of both monomers into the polymer chain. The ${ }^{1} \mathrm{H}$ NMR analysis of the reaction mixture allowed for the determination of monomer conversions (Table 1) using the integration of vinyl proton signals assigned to unreacted TMAMA and MMA (6.2-6.1 ppm and 6.1-6.0 ppm, respectively) relative to signals corresponding to the protons in substituents (both reacted and unreacted monomers), i.e., $9 \mathrm{H}$ in $-\left(\mathrm{CH}_{3}\right)_{3} \mathrm{~N}^{+}$and $3 \mathrm{H}$ in $-\mathrm{OCH}_{3}$, respectively. The conversion values could then be used to calculate the other parameters, including the polymerization degree, the ionic unit contents, and the polymer molecular weight (Table 1). The compositions of the final copolymers C1, C2, and C3 containing 24\%, 49\%, and 75\% TMAMA units, respectively, were guaranteed by properly assumed initial ratio of monomers. The controlled polymerization was also verified by the size-exclusion chromatography (SEC) results, supporting low dispersity indices of the polymers with longer chains $\left(\bigoplus<1.4\right.$ at $\left.\mathrm{DP}_{\mathrm{n}}>450\right)$. The exception for $\mathrm{C} 1$ suggests that a lower reaction rate in a system containing predominantly MMA promoted the occurrence of side reactions (Table 1). 


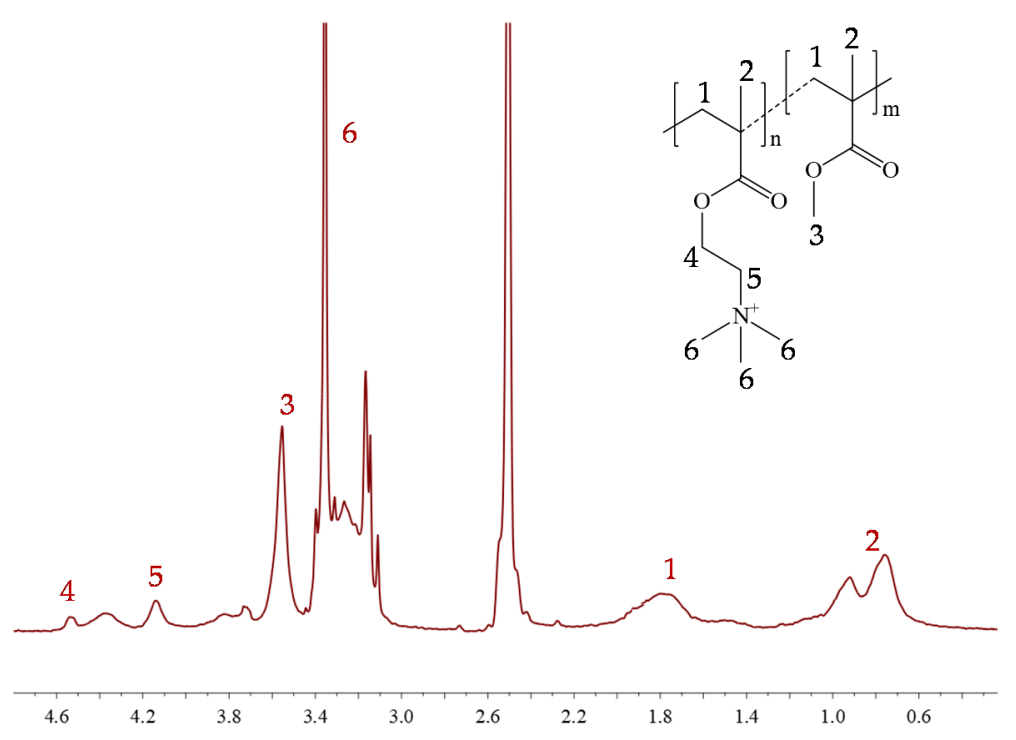

Figure 2. ${ }^{1} \mathrm{H}$ NMR spectrum of linear copolymer of TMAMA/Cl $\mathrm{C} 1$, where $\mathrm{n}$ is $\mathrm{DP}_{\mathrm{M} 1}$ and $\mathrm{m}$ is $\mathrm{DP} \mathrm{P}_{\mathrm{M} 2}$.

The amphiphilic nature of the linear copolymers was investigated via goniometry; specifically, measuring the interfacial tension (IFT) of polymer aqueous solution in a concentration series $(C=0.008-0.5 \mathrm{mg} / \mathrm{mL})$. The crossing point on a plot of IFT values vs. $\log \mathrm{C}$ of measured samples was determined as the critical micelle concentration (CMC; Figure 3a), which defines the polymer's ability to form micellar structures in aqueous solution. The CMC values increased as the content of TMAMA ionic units increased (Figure 3b).

(a)

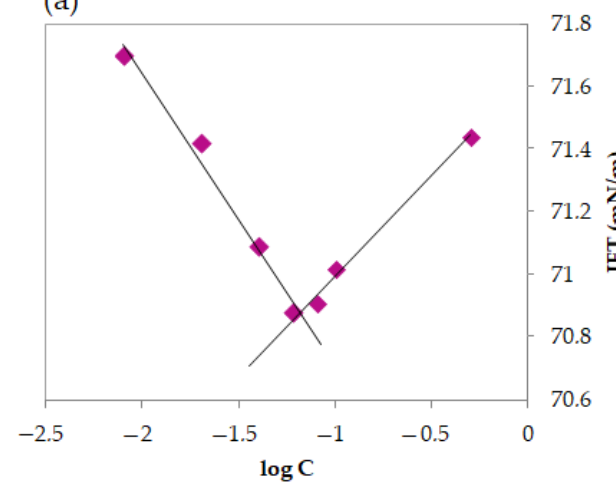

(b)

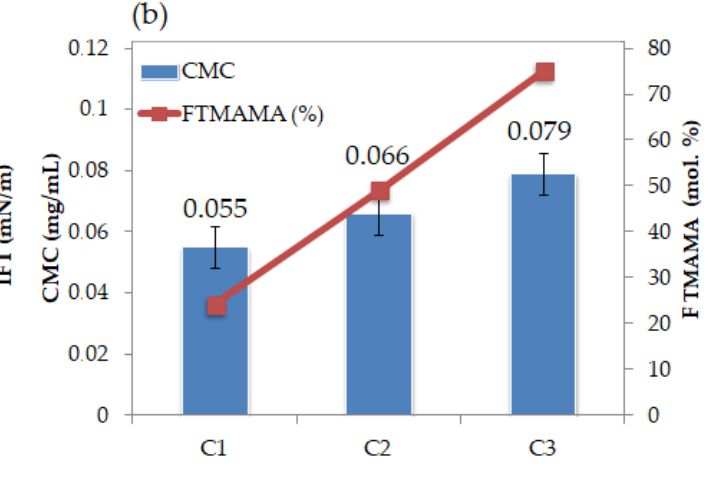

Figure 3. (a) Variation in the interfacial tension with the logarithm of the linear copolymer C2 concentration in aqueous solution at $25^{\circ} \mathrm{C} ;(\mathbf{b})$ influence of polymer chain length on critical micelle concentration (CMC) value.

The presence of cationic units with chloride counter ions statistically distributed along the polymer chain was advantageous for the anion exchange reaction to generate pharmaceutical activity. The drug in ionic form was introduced to the polymer matrix by dissolving and mixing with the polymer for $48 \mathrm{~h}$. The studied pharmaceutical salts (i.e., sodium or potassium PAS, CLV, PIP, and FUS) were selected based on their antibacterial and bacteriostatic activity. The introduction of pharmaceutical anion (PhA) into chloride based copolymers was analyzed by Fourier-transform infrared spectroscopy (FT-IR), where the characteristic bands were identified. Before anion exchange the chloride copolymers were recognized by the presence of absorption peaks corresponding to $\mathrm{C}-\mathrm{O}$ and $\mathrm{C}=\mathrm{O}$ stretching vibration of ester groups (1150 $\mathrm{cm}^{-1}$ and $1720 \mathrm{~cm}^{-1}$, respectively), C-H $\left(1450 \mathrm{~cm}^{-1}\right.$, $\left.2800-3100 \mathrm{~cm}^{-1}\right)$, as well as C-N $\left(950 \mathrm{~cm}^{-1}\right)$ in the quaternary nitrogen group of TMAMA units (Figure S1). After anion exchange the new bands appeared at $800-1000 \mathrm{~cm}^{-1}$ and $1600 \mathrm{~cm}^{-1}$ (aromatic $\mathrm{C}=\mathrm{C}$ ) due to PAS and PIP, at $1550 \mathrm{~cm}^{-1}$ (alkene $\mathrm{C}=\mathrm{C}$ ) due to CLV and 
FUS, $1250 \mathrm{~cm}^{-1}$ (C-S) due to PIP. Moreover, a broad signal characteristic for O-H and N-H stretching vibrations $\left(3250-3600 \mathrm{~cm}^{-1}\right)$ was detected as the representative for all types of anions, whereas signal in range of $2845-3000 \mathrm{~cm}^{-1}$ was significantly more intense in the system with CLV due to content of large number of aliphatic and cyclic C-H bonding.

A new characteristic signals assigned to the bonded drugs were also detected in the ${ }^{1} \mathrm{H}$ NMR spectra (see detailed data of chemical shifts in the Supporting Materials). The protons becoming from the polymer matrix are observed at low ppm region (4.58-0.46 ppm, Figure S2a). After anion exchange to $\mathrm{PAS}^{-}$the conjugation was confirmed by the presence of signals in the range of 4.9-7.3 ppm, including protons from benzene ring (Figure S2b). In the case of CLV, PIP, and FUS (Figure S2c-e), the protons corresponding to PhA were overlapped with those for the copolymer carrier. Theoretically, the pharmaceutical anions could generate the nucleophilic attack on the carbon of carbonyl group to form carboxylic groups in the copolymer. However, both carboxylic acids and their deprotonated forms are rather weak nucleophiles, thus they should not be effective in the case of the detachment of methyl and 2-trimethylammonium ethyl groups situated at ester bonding. The lack of signal at higher chemical shifts (12-13 ppm) in the ${ }^{1} \mathrm{H}$ NMR spectra of the ionic conjugates confirms that the acidic hydrolysis was not activated (Figure S2).

The degree of anion exchange was determined based on the drug content (DC), which was evaluated with ultraviolet-visible light spectroscopy (UV-Vis). DC values represent the percentage contribution of pharmaceutical ions in the copolymer (Table 2). In the exchange reactions, the least effective ionic drug was FUS (7-11\%), but CLV, PAS, and PIP, demonstrated satisfactory degrees of exchange, reaching levels of $65-95 \%, 59-82 \%$, and $42-48 \%$, respectively. These results suggest that the nature of the anion has a significant impact on the degree of exchange, and that pharmaceutic compounds with less steric hindrance (i.e., PAS and CLV) were especially beneficial in the anion replacement reaction. Additionally, the drug content was improved when the TMAMA content was increased to $50 \%$, but a larger quantity of ionic units limited the exchange yield (Figure 4 ). The PIP and FUS anions may have encountered problems finding the chloride exchange sites because they are larger molecules. The structures of PAS, CLV, and PIP contain the nitrogen atoms, which provide their higher coordination number, and they enhance the anion affinity to trimethylammonium substituents. As a result, these pharmaceutical anions were introduced in large amounts. A different effect was noticed in the case of FUS, which is a rigid structure of four conjugated rings, thus exhibiting lower affinity for the hydrophilic moieties. These results are in good correlation with another important factor, which is the water solubility of the salt/anion, which is the most limited for FUS, and then increases in the order PIP $<$ PAS $<$ CLV, according to Databank Online.

Table 2. Data for exchanged and released pharmaceutical anion (PhA) in the TMAMA-based polymers.

\begin{tabular}{|c|c|c|c|c|c|c|c|c|}
\hline \multirow[b]{3}{*}{ No. } & \multicolumn{4}{|c|}{ Drug Exchange } & \multicolumn{4}{|c|}{ Drug Release } \\
\hline & \multicolumn{4}{|c|}{$\begin{array}{c}\text { DC }(\%) \\
\text { (Concentration of Introduced PhA } \\
(\mu \mathrm{g} / \mathrm{mL}))\end{array}$} & \multicolumn{4}{|c|}{$\begin{array}{c}\text { Amount of Released PhA (\%) } \\
\text { (Concentration of Released PhA } \\
(\mu \mathrm{g} / \mathrm{mL}))\end{array}$} \\
\hline & PAS $^{-}$ & $\mathrm{CLV}^{-}$ & PIP- $^{-}$ & FUS $^{-}$ & PAS $^{-}$ & $\mathrm{CLV}^{-}$ & PIP- $^{-}$ & FUS $^{-}$ \\
\hline $\mathrm{C} 1$ & $\begin{array}{c}75.8 \\
(16.9)\end{array}$ & $\begin{array}{c}65.6 \\
(14.6)\end{array}$ & $\begin{array}{l}42.6 \\
(9.5)\end{array}$ & $\begin{array}{c}7.8 \\
(1.7)\end{array}$ & $\begin{array}{l}32.7 \\
(5.3)\end{array}$ & $\begin{array}{c}5.3 \\
(0.8)\end{array}$ & $\begin{array}{c}8.1 \\
(0.8)\end{array}$ & $\begin{array}{l}65.7 \\
(1.1)\end{array}$ \\
\hline $\mathrm{C} 2$ & $\begin{array}{c}82.2 \\
(18.2)\end{array}$ & $\begin{array}{c}95.3 \\
(21.2)\end{array}$ & - & $\begin{array}{c}9.7 \\
(2.2)\end{array}$ & $\begin{array}{l}34.9 \\
(6.4)\end{array}$ & $\begin{array}{c}9.3 \\
(2.0)\end{array}$ & - & $\begin{array}{l}21.1 \\
(0.5)\end{array}$ \\
\hline C3 & $\begin{array}{l}59.3 \\
(6.6)\end{array}$ & $\begin{array}{c}81.7 \\
(18.1)\end{array}$ & $\begin{array}{c}47.5 \\
(10.5)\end{array}$ & $\begin{array}{l}10.7 \\
(2.4)\end{array}$ & $\begin{array}{l}45.4 \\
(3.0)\end{array}$ & $\begin{array}{c}7.7 \\
(1.4)\end{array}$ & $\begin{array}{c}7.3 \\
(0.8)\end{array}$ & $\begin{array}{l}49.5 \\
(1.2)\end{array}$ \\
\hline
\end{tabular}

$\mathrm{DC}$ is drug content; $\mathrm{PAS}^{-}$is $p$-aminosalicylic, $\mathrm{CLV}^{-}$is clavulanic, $\mathrm{FUS}^{-}$is fusidic, and $\mathrm{PIP}^{-}$is piperacillin anion. 


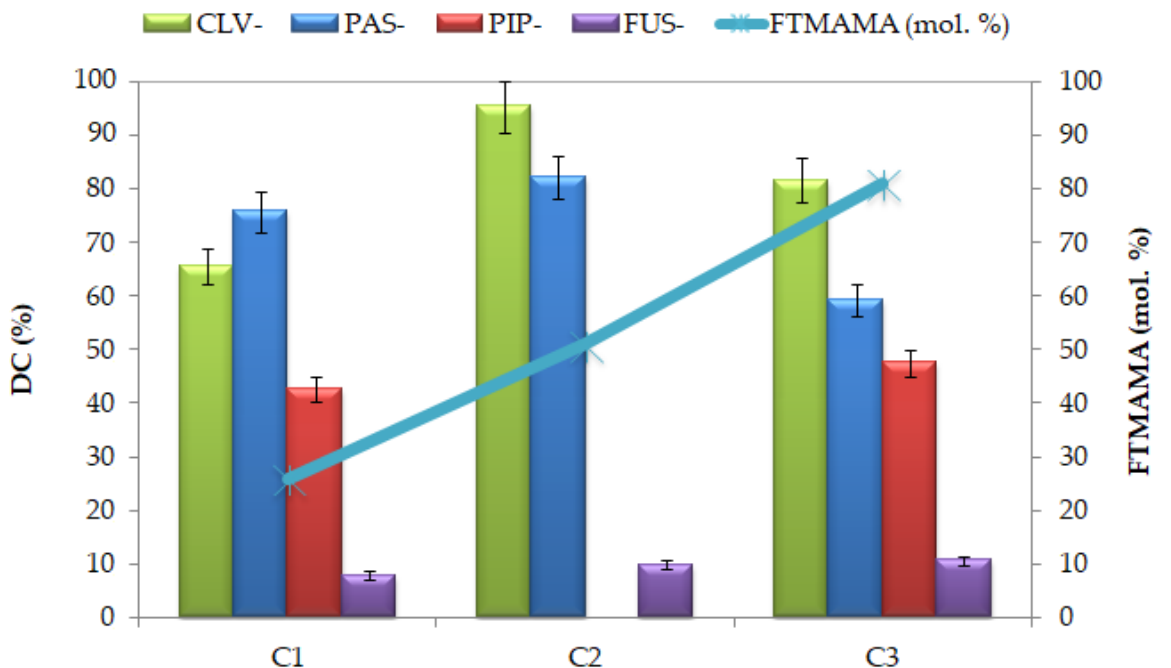

Figure 4. Effect of anion type and content of ionic fractions on the drug content.

The hydrophilicities of the introduced pharmaceutical anions were evaluated by determining the water contact angle via goniometry using the sessile drop method. Aqueous solutions of the polymer systems $(0.3 \mathrm{mg} / \mathrm{mL}$ in methanol) were applied to thoroughly cleaned glass plates by a spin-coating method, where the centrifugal force allowed for the homogeneous distribution of polymer across the surface to form a film. The water contact angles (WCA) values (presented in Figure 5) showed a decreasing trend with increasing content of ionic units $\left(\mathrm{F}_{\mathrm{M} 1}\right)$ for all studied systems, including those with the pharmaceutical anions.

C1

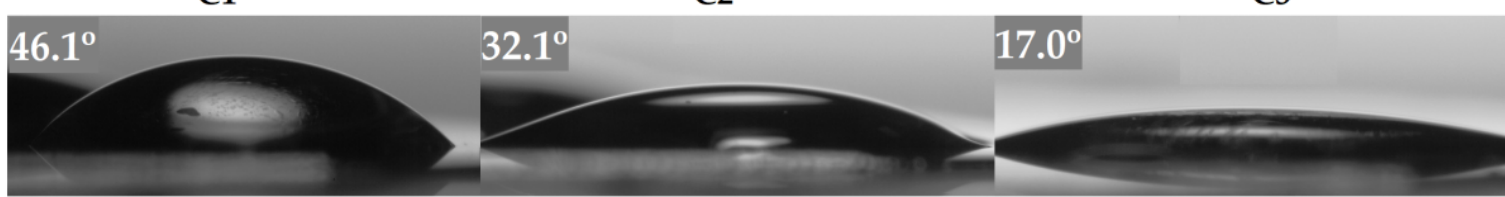

PAS $^{-}$
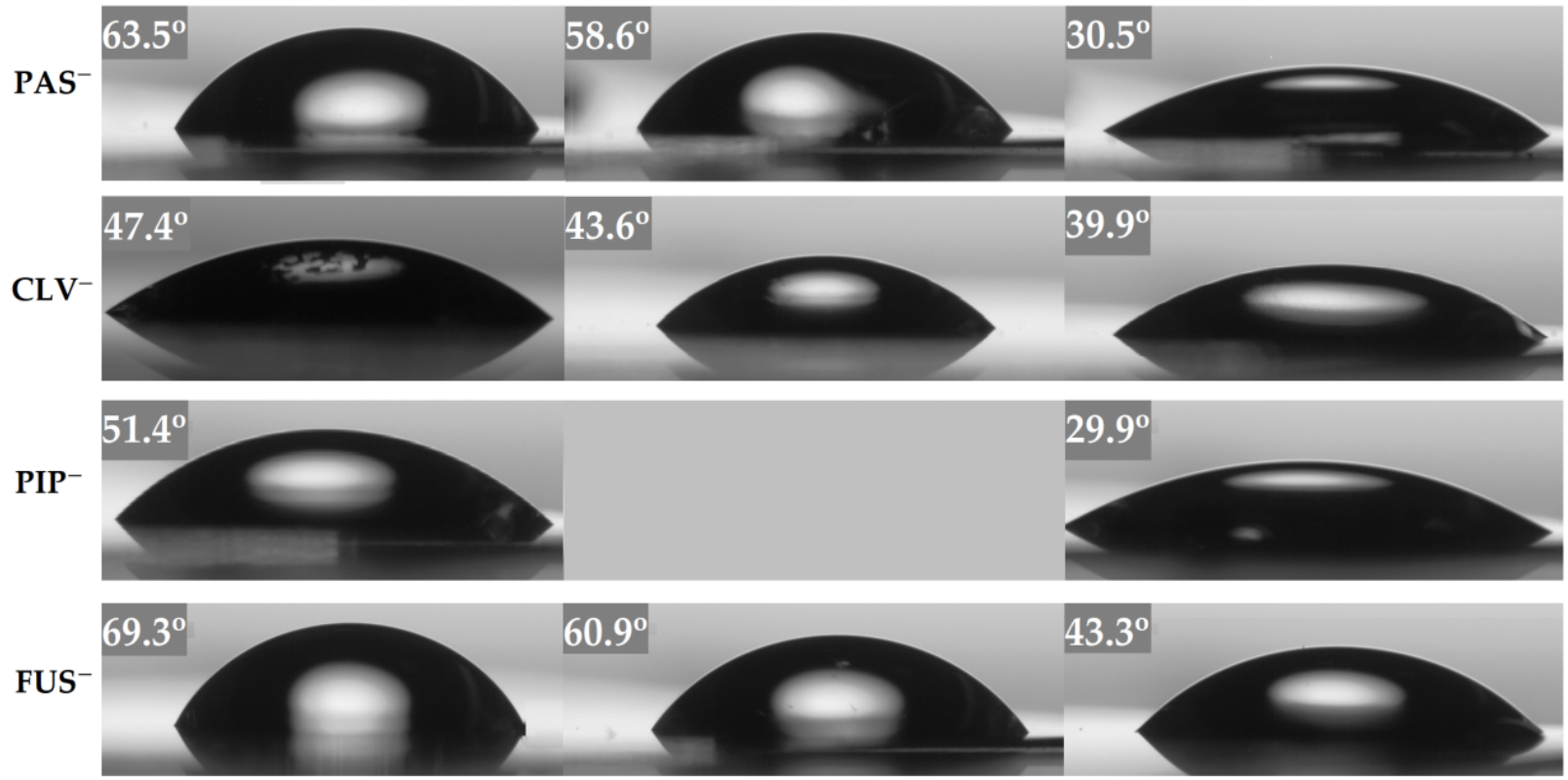

Figure 5. Changes in surface wettability depending on the copolymer and counter-ion, illustrated by goniometry camera. 
The WCA values for polymer matrices containing $\mathrm{Cl}$ anions changed from $46^{\circ}$ to $17^{\circ}$, indicating that they were hydrophilic systems. The same correlation between WCA and TMAMA content has been described previously for graft copolymers with TMAMA units in the side chains [42], but their wettability was lower than that of the linear copolymers studied herein because of the hydrophobic backbone. After anion exchange, the wettability of the polymer films was reduced, yielding higher WCA values relative to their polymer matrices, meaning that the selected drugs did not improve the hydrophilicity of ionic conjugates. Among the tested systems, the FUS-bearing polymers were the most dissimilar $\left(43-69^{\circ}\right)$, although the drug content was the smallest, indicating the specificity of the steroid structure of the introduced anions. Figure 5 shows the visual changes in the contact angles of the individual systems, which illustrate the differences in the wettability of surfaces covered with PIL layers. The composition of the polymer matrix, the type of drug, and the exchange efficiency influence the hydrophilicity of the system. These parameters are also responsible for the ratios of TMAMA/PhA to TMAMA/Cl units present in the polymer chain due to incomplete exchange.

The physicochemical characteristics of the chloride-based copolymers and their ionic drug conjugates were evaluated using dynamic light scattering (DLS) measurements. Before exchange, the hydrodynamic diameters $\left(D_{h}\right)$ of copolymer particles were ranged in 240-300 nm showing no dependency on the ionic content. Copolymer C1 containing PAS and PIP showed similar behavior, forming two equal-volume fractions, with particle sizes of 274 and $12 \mathrm{~nm}, 291$ and $9 \mathrm{~nm}$, respectively. This result indicates that the selfassembled micelles easily aggregated because of the high content of hydrophobic fraction in $\mathrm{C} 1\left(\mathrm{~F}_{\mathrm{MMA}}=75 \%\right)$. In contrast, $\mathrm{C} 2$ and $\mathrm{C} 3$ the fraction of smaller particles $\left(\mathrm{D}_{\mathrm{h}} \sim 20 \mathrm{~nm}\right)$ prevailed (67-80\%). Additionally, the particles were characterized by a low size distribution $(\mathrm{PDI}=0.38-0.46)$. In the copolymers with CLV, one dominant fraction was observed $(75-80 \%)$, wherein the particles reached larger sizes $(169-306 \mathrm{~nm})$ and their polydispersity indices were higher (0.8-1). However, C1/CLV particles were smaller than C1 conjugated with PAS or PIP. The formation of large particles as the higher level of self-assemblies was observed due to aggregation effect of micelles in water solution. The self-organized linear TMAMA copolymers probably form the superstructures of entangled chains with statistically distributed ionic and hydrophobic groups, which can be situated in their outer part. Thus, the external hydrophobic moieties participating in the $\pi$-stacking interaction and hydrogen bonding between hydrophilic moieties (especially in the conjugates), were responsible for attraction polymer assemblies to result in aggregates $(>470 \mathrm{~nm}, 20 \%)$ and super-aggregates $(>1000 \mathrm{~nm},<10 \%)$. The details are presented in Table 3 and illustrated by the DLS histograms in Figure 6.

Table 3. Hydrodynamic diameters of poly(ionic liquid) (PIL) particles determined by dynamic light scattering (DLS) ${ }^{\text {a }}$.

\begin{tabular}{|c|c|c|c|c|c|c|c|c|c|c|c|c|}
\hline \multirow[t]{2}{*}{ No. } & \multicolumn{3}{|c|}{$\mathrm{Cl}^{-}$} & \multicolumn{3}{|c|}{ PAS $^{-}$} & \multicolumn{3}{|c|}{$\mathrm{CLV}^{-}$} & \multicolumn{3}{|c|}{ PIP $^{-}$} \\
\hline & $\begin{array}{c}D_{h} \\
(\mathrm{~nm})\end{array}$ & $\begin{array}{c}\mathbf{f} \\
(\%)\end{array}$ & PDI & $\begin{array}{c}D_{h} \\
(n m)\end{array}$ & $\begin{array}{c}\mathrm{f} \\
(\%)\end{array}$ & PDI & $\begin{array}{c}D_{h} \\
(\mathrm{~nm})\end{array}$ & $\begin{array}{c}\mathrm{f} \\
(\%)\end{array}$ & PDI & $\begin{array}{c}D_{h} \\
(n m)\end{array}$ & $\begin{array}{c}f \\
(\%)\end{array}$ & PDI \\
\hline \multirow{2}{*}{$\mathrm{C} 1$} & 239 & 62.7 & \multirow{2}{*}{0.723} & 274 & 49.9 & \multirow[b]{2}{*}{0.605} & 169 & 73.4 & \multirow{2}{*}{0.809} & 291 & 43.7 & \multirow{2}{*}{0.496} \\
\hline & $1-5$ & 35.6 & & 12 & 47.4 & & 7 & 20.8 & & 9 & 48.0 & \\
\hline \multirow{2}{*}{$\mathrm{C} 2$} & 301 & 93.9 & \multirow{2}{*}{0.471} & 24 & 75.3 & \multirow{2}{*}{0.442} & 306 & 80.9 & \multirow{2}{*}{1.000} & \multirow{2}{*}{ - } & \multirow{2}{*}{-} & \multirow{2}{*}{ - } \\
\hline & 5 & 6.1 & & 926 & 22.1 & & 15 & 17.0 & & & & \\
\hline \multirow{2}{*}{ C3 } & 237 & 76.3 & \multirow{2}{*}{0.506} & 20 & 67.2 & \multirow{2}{*}{0.457} & 217 & 75.6 & \multirow{2}{*}{0.791} & 23 & 80.5 & \multirow{2}{*}{0.381} \\
\hline & 2 & 23.7 & & 475 & 20.6 & & 16 & 23.8 & & 772 & 19.5 & \\
\hline
\end{tabular}

Where $\mathrm{f}$ is an fraction content of particles, ${ }^{\mathrm{a}}$ measurements based on the intensity at a copolymer concentration in aqueous solution of $1 \mathrm{mg} / \mathrm{mL}$. 

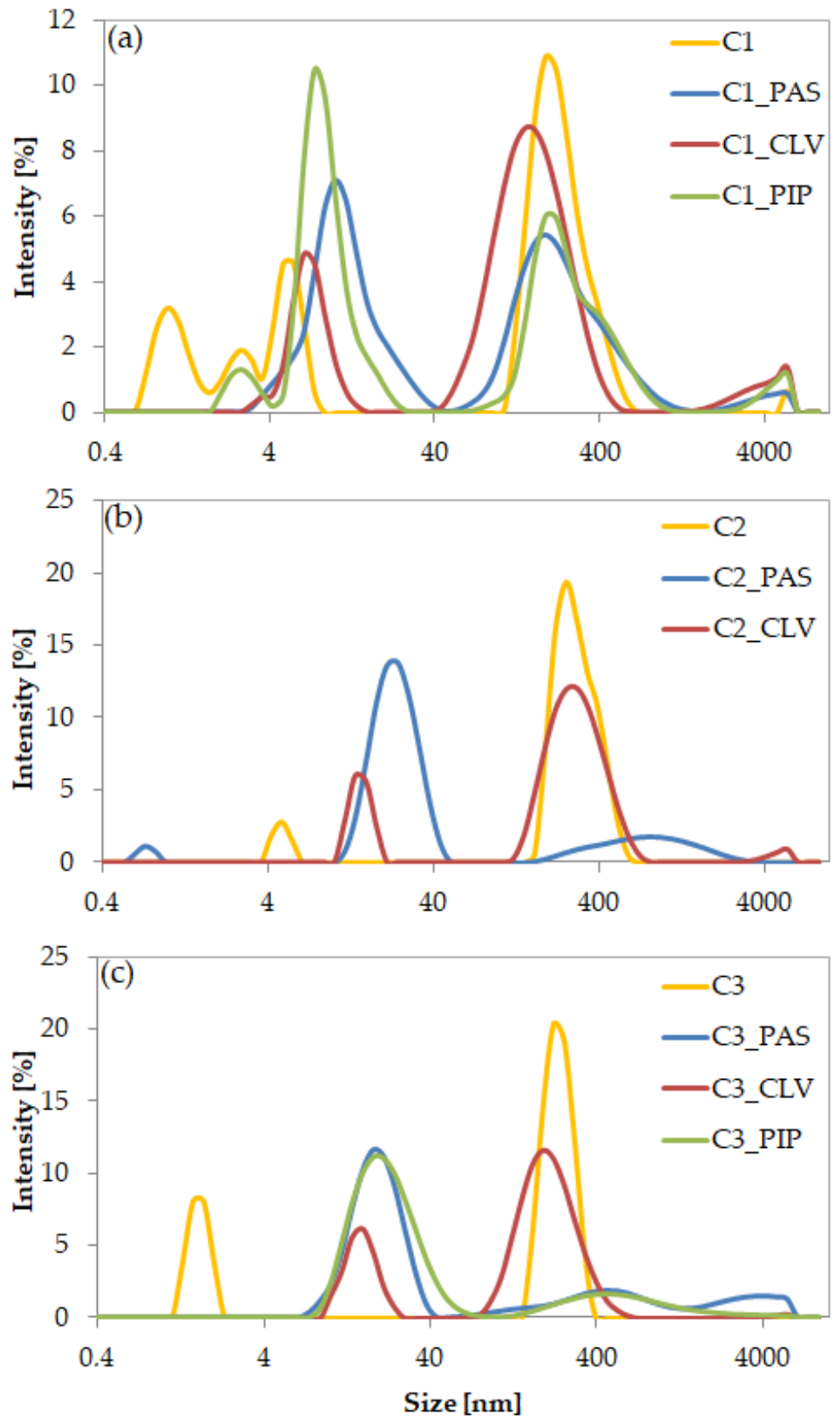

Figure 6. DLS histograms for particles of (a) C1, (b) C2, and (c) C3 systems in deionized water at $25{ }^{\circ} \mathrm{C}$.

The release of the selected drugs in non-ionic forms has been reported for the nonionic polymers used in the encapsulation of these compounds via physical interactions, for example: poly( $\varepsilon$-caprolactone)-b-polyethylene glycol- $b$-poly( $\varepsilon$-caprolactone) polymersomes with loaded clavulanic acid (16\%), which was released in 35\% after $24 \mathrm{~h}$ and $60 \%$ after 170 h [47], poly(ethylene glycol) methyl ether- $b$-poly (lactide-co-glycolide) with loaded PIP/tazobactam to design the effective antibiofilm [48], poly(DL-lactic-co-glycolic acid) and poly(3-hydroxybutyric acid-co-3-hydroxyvaleric acid) microspheres with encapsulated fusidic acid (76-89\%), which was released up to $80 \%$ [49].

Previous in vitro studies into the mechanism of anionic drug release from ionic carriers have indicated that the phosphate anions from phosphate buffered saline (PBS) can exchange with the biologically active anions conjugated to the polymer matrix [36]. Systems based on TMAMA copolymers have been investigated for delivery of salicylate or sulfacetamide counterions [39]. As it was noticed, the anion exchange properties strongly 
depended on the nature of both ionic polymer and ionic drug. Thus, the chloride anions were exchanged by the salicylate ones in $50 \%$, and then they were exchanged by phosphates anions in 35-60\% demonstrating the "burst" effect within $4 \mathrm{~h}$, whereas in the case of sulfacetamide systems PhA introduction was efficient in $98 \%$, but its release occurred in only $11 \%$.

During drug release via dialysis in $\mathrm{PBS}\left(\mathrm{pH}=7.4\right.$ in $\left.37^{\circ} \mathrm{C}\right)$, the samples were collected at designated time intervals, and the maximum absorptions of the free pharmaceutics were measured using UV-Vis. The burst release of $\mathrm{PAS}^{-}$and $\mathrm{CLV}^{-}$was observed around 1-1.5 $\mathrm{h}$, and the release continued up to $4 \mathrm{~h}$, when small changes in the kinetics profiles resulted in the plateau state. For the systems containing PIP $^{-}$and $\mathrm{FUS}^{-}$, which have large steric hindrance, the release process occurred over a longer time, as indicated by the visible changes in free drug concentration detected for up to $48 \mathrm{~h}$, especially for PIP systems (Figure 7). Generally, four different release profiles depending on the burst drug release point and more or less suddenly attained plateau are demonstrated. According to that the PAS, FUS, and CLV based systems in comparison to polymers bearing PIP seem to be more effective in the release rate of those anions. The rapid release of the drug in the first $4 \mathrm{~h}$ suggests their localization in the external groups, whereas the remaining anions could be trapped inside. This hypothesis can be concluded especially for PIP systems, where the effective drug release followed after $1 \mathrm{~h}$. The remaining drug anions trapped inside the core need higher ionic strength to suppress interactions and then to diffuse though the entangled matrix, which can be additionally limited by the rigidity and steric hindrance of pharmaceutic molecule. The best delivery properties considering both drug content and amount of the released drug were exhibited by PAS systems, because $60-80 \%$ of the drug was attached and $33-46 \%$ was released. This was associated with a high concentration of released drug (3.0-6.4 $\mu \mathrm{g} / \mathrm{mL}$; Table 2). Although the systems with FUS $^{-}$could exchange large amounts of pharmaceutics with phosphate anions (21-66\%) probably due to repulsive effect magnified by steric structure of FUS, the low drug content $(\sim 2 \mu \mathrm{g} / \mathrm{mL})$ led to a significantly lower concentration of the released drug $(0.5-1.2 \mu \mathrm{g} / \mathrm{mL})$. Low release percentage levels were achieved by the systems containing $\mathrm{CLV}^{-}$and $\mathrm{PIP}^{-}$ $(\sim 10 \%)$ corresponding to $0.8-2.0 \mathrm{mg} / \mathrm{mL}$, in spite of a relatively large drug contents in $\mathrm{CLV}^{-}$and $\mathrm{PIP}^{-}$systems (mean $\sim 80 \%$ vs. $40 \%$ ). This opposite behavior in relation to FUS can be also explained by the way of anions conjugation and high stability of conjugates due to strong attraction in entangled core and lower coordination number of phosphate anions.

The previous tested micelles based on TMAMA grafted copolymers formed micelles, where the core was composed mainly of hydrophobic backbone; in turn, the shell included grafted chains with cationic groups. Thus, the pharmaceutical anions were arranged only outside the core. In comparison with linear copolymers, the easier access to the pharmaceutical ions in grafted ones should facilitate drug release, but this aspect is much more composite due to higher stability of the graft polymer with the micelle-like structure. The exchange of $\mathrm{Cl}^{-}$onto $\mathrm{PAS}^{-}$and $\mathrm{CLV}^{-}$in the graft polymer matrix was yielded at $31-64 \%$ and $79-100 \%$, respectively, and then the exchange onto phosphate anions was carried out during drug release in $20-42 \%(3-9 \mu \mathrm{g} / \mathrm{mL}$ from $1 \mathrm{mg}$ of drug conjugates) for

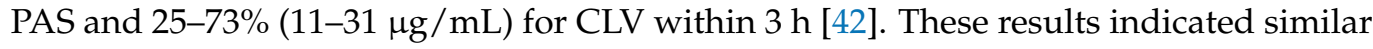
levels of PAS release independently on polymer topology, whereas the percentage amounts of released CLV was $\sim 10$ times lower for the linear polymers. The burst effect was much less significant for graft copolymers, especially those with higher grafting degree. It shows that the change in structural parameters of copolymer carrier caused by macromolecule topology can be strategic for individual exchange and release properties for the same pharmaceutical anion.

Different mathematical models were applied to describe the in vitro drug release. The fitting levels for kinetics profiles were interpreted by correlation coefficients $\left(R^{2}\right)$, which determined adequate model describing the release mechanisms. The release of PAS, CLV, PIP, and FUS anions represented by first-order kinetics $\left(\mathrm{R}^{2}=0.75-0.95,0.98\right.$, $0.95-0.97,0.84-0.99$, respectively) indicated the dependence of drug release rate on the 
concentration (Figure 8a-d). The Higuchi model, presented as a function of the percentage of remaining anions in relation to the square root of time (Figure 8e-h), was the most fitted for PIP conjugates showing the highest values of the $\mathrm{R}^{2}$ above 0.97 . However, the CLV and FUS systems also achieved good correlation with this model $\left(R^{2}=0.81-0.99\right)$. Hence, it can be postulated that the anion drug release followed diffusion controlled mechanism. Moreover, it was found that the Korsmeyer-Peppas model, which distinguishes Fickian and non-Fickian diffusion estimated by the diffusion exponent $(n$, calculated from equation $\mathrm{M}_{\mathrm{t}} / \mathrm{M}=k t^{n}$, Table S1) similarly to Higuchi model, was also represented by a high fitting degree (0.8-0.99; Figure S3). System C3/PIP indicated the diffusion exponent value in the range of equal $0.45<n<0.89$, so the drug release occurred by non-Fickian diffusion, whereas in the case of $\mathrm{C} 1 / \mathrm{PIP}$ it was higher than 0.89 , which implies non-Fickian super case-II transport. The release of PhA by other systems can be described by quasi-Fickian process $(n \leq 0.45)$. These results mean that the diffusion process of released anions is slower than the anion exchange as consequence of the break of ionic bonding between PhA and trimethylammonium moieties in the polymer.
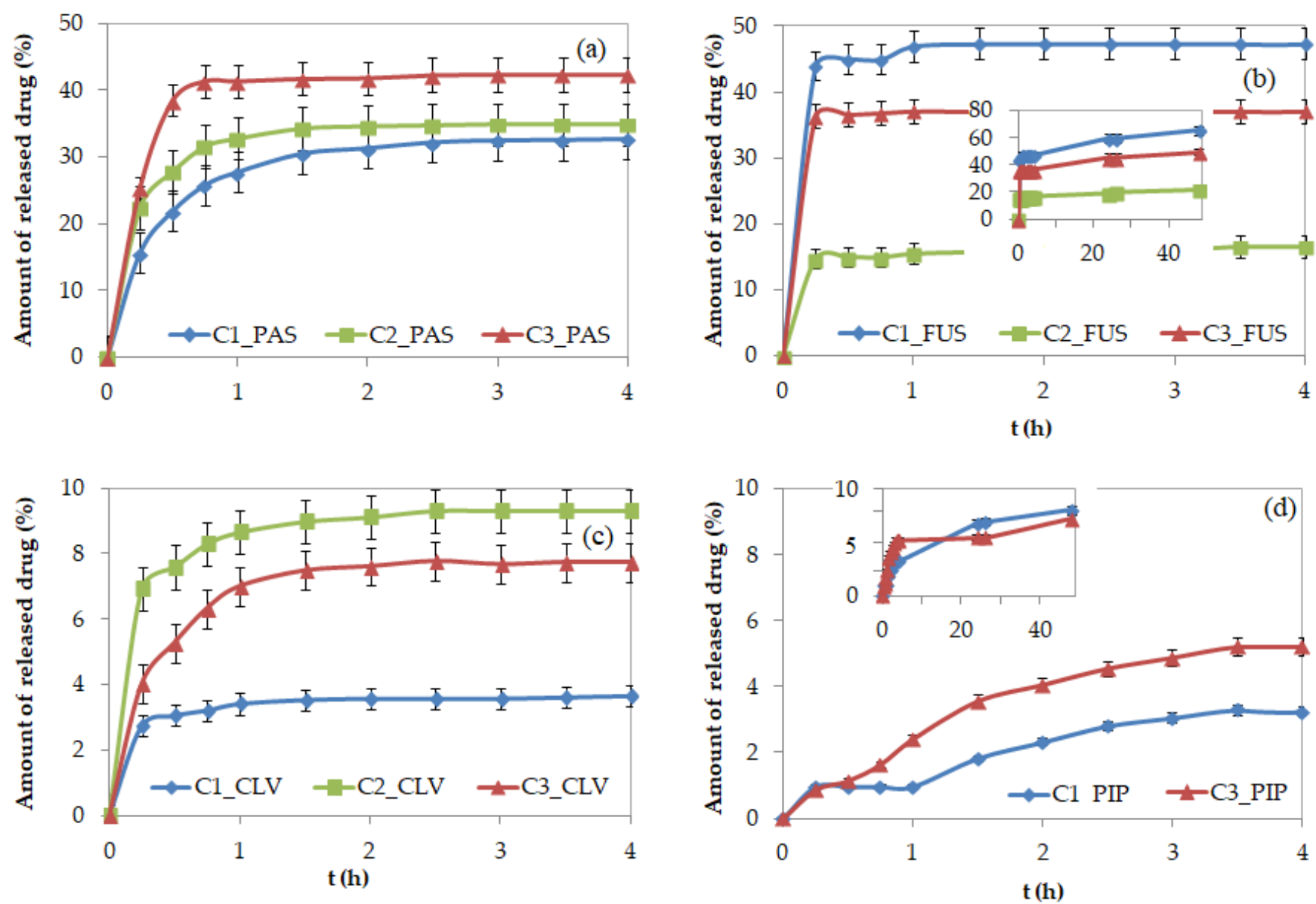

Figure 7. Kinetic release profiles of (a) PAS, (b) FUS, (c) CLV, and (d) PIP anions from conjugates based on PILs. 

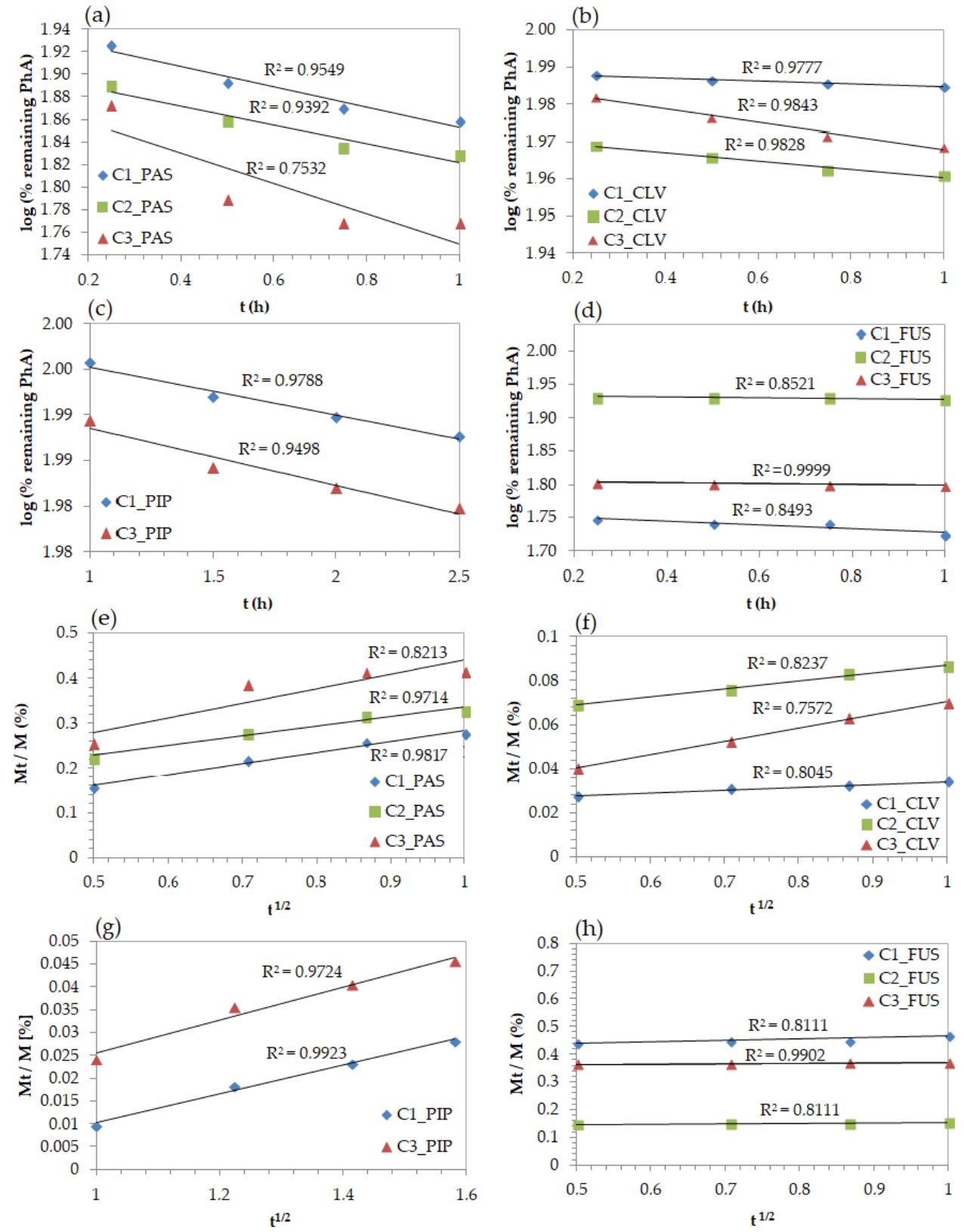

Figure 8. Kinetics profiles by models of first order $(\mathbf{a}-\mathbf{d})$, and Higuchi's (e-h) for release of PAS, CLV, PIP, and FUS anions from conjugates based on PILs.

\section{Materials and Methods}

The methyl methacrylate (MMA; Alfa Aesar, Warsaw, Poland) was dried using molecular sieves (type $4 \AA$, Chempur, Piekary Ślaskie, Poland). The [2-(methacryloyloxy)ethyl]trimethylammonium chloride (TMAMA/Cl; $80 \%$ aq. solution, Sigma-Aldrich, Poznań, Poland) was dried to a constant weight under reduced pressure. Methanol and tetrahydrofuran (THF) were purchased from Chempur (Piekary Ślaskie, Poland) and dried over the same molecular sieves as MMA. Copper(I) bromide (CuBr; Fluka, 98\%, Steinheim, Germany) was purified using a procedure described previously in the literature [42]. $N, N, N^{\prime}, N^{\prime \prime}, N^{\prime \prime}$-pentamethyldiethylenetriamine (PMDETA, 98\%), ethyl 2-bromoisobutyrate $(\mathrm{EBiB}, 98 \%)$, potassium clavulanate $(\mathrm{KCLV})$, and bis(trifluoromethane)sulfonimide lithium salt $\left(\operatorname{LiTf}_{2} \mathrm{~N}\right)$ were obtained from Sigma Aldrich (Poznań, Polska). Sodium $p$-aminosalicylate (NaPAS, 98\%), sodium piperacillin (NaPIP, 99\%), and sodium fusidate (NaFUS, 98.8\%) were purchased from Alfa Aesar (Warsaw, Poland) and used without further purification. 


\subsection{Characterization}

${ }^{1} \mathrm{H}-\mathrm{NMR}$ spectra were recorded using a UNITY/NOVA spectrometer $(300 \mathrm{MHz}$, Varian, Mulgrave, Victoria, Australia). The measurements were executed in deuterated dimethyl sulfoxide (DMSO- $\mathrm{d}_{6}$ ) with tetramethylsilane (TMS) as the internal standard. The molecular weight $\left(\mathrm{M}_{\mathrm{n}}\right)$ and dispersity index $(\mathrm{D})$ were estimated using size exclusion chromatography (SEC) in THF (1100 Agilent 1260 Infinity with differential refractometer MDS RI detector, Agilent Technologies, Santa Clara, CA, USA) at $40{ }^{\circ} \mathrm{C}$ with a flow rate of $0.8 \mathrm{~mL} / \mathrm{min}$ using a pre-column guard $(5 \times 7.5 \mathrm{~mm})$ and a PLGel $5 \mu \mathrm{m}$ MIXEDC 300 column $(7.5 \times 300 \mathrm{~mm})$. The calculations were based on polystyrene standards (580-300,000 g/mol). Fourier-transform infrared spectroscopy (FT-IR) was conducted with Spectrum Two 1000 FT-IR Infrared Spectrometer with attenuated total reflection (ATR) (Perkin Elmer, Waltham, MA, USA). The critical micelle concentration (CMC) was determined via interfacial tension measurements of aqueous polymer solutions with concentrations in the range of $8 \times 10^{-3}$ to $0.5 \mathrm{mg} / \mathrm{mL}$, which were performed with the pendant drop method using a goniometer (OCA 15EC, DataPhysics, Filderstadt, Germany). SCA20_U software was used for data collection and processing. The same software module was also employed for the water contact angle (WCA) measurements carried by the sessile drop method, in which a drop of water $(4 \mu \mathrm{L})$ was placed on the polymer film. The polymer film was prepared by spin coating the polymer solution in methanol $(0.3 \mathrm{mg} / \mathrm{mL})$, which was applied on degreased glass plates. The hydrodynamic diameter $\left(D_{h}\right)$ of particles and polydispersity index (PDI) were measured by dynamic light scattering (DLS) using a Zetasizer Nano-S90 instrument (Malvern Technologies, Malvern, UK). He-Ne laser operated at $4 \mathrm{~mW}$ was the source of light scattered at $633 \mathrm{~nm}$. Samples diluted in water $(1.0 \mathrm{mg} / \mathrm{mL})$ after filtration (MCE Syringe Filters, hydrophilic M.E. Cellulose membrane with pore diameter: $0.45 \mu \mathrm{m}$ ) were introduced into poly(methyl methacrylate) cells, which were placed in the compartment thermostated at $25^{\circ} \mathrm{C}$. Each measurement was repeated three times to obtain an average value. Data were analyzed using the cumulant method. The drug release process was monitored by ultraviolet-visible spectroscopy (UV-Vis; Evolution 300 spectrometer, Thermo Fisher Scientific, Waltham, MA, USA) on the samples acquired at suitable time intervals. This method allowed the determination of the drug content (DC) and the amount of released pharmaceutical anions $\left(\mathrm{PAS}^{-}, \mathrm{CLV}^{-}, \mathrm{PIP}^{-}\right.$, or $\mathrm{FUS}^{-}$).

\subsection{Synthesis of Linear Copolymers Bearing $\mathrm{Cl}^{-}$(Example for C1)}

Comonomers TMAMA ( $2 \mathrm{~g}, 9.63 \mathrm{mmol})$ and MMA $(3.08 \mathrm{~mL}, 28.88 \mathrm{mmol})$, methanol $(3 \mathrm{~mL})$, and THF $(1 \mathrm{~mL})$ were added into a Schlenk flask. The mixture was degassed by two freeze-pump-thaw cycles. Then, $\mathrm{EBiB}(9.52 \mu \mathrm{L}, 0.06 \mathrm{mmol})$ was added as the ATRP initiator, and the degassing cycle was repeated once again before the initial sample $(0.1 \mathrm{~mL})$ was taken. The reaction was catalyzed by a CuBr/PMDETA complex $(9.21 \mathrm{mg}$, $0.06 \mathrm{mmol} / 13.40 \mu \mathrm{L}, 0.06 \mathrm{mmol})$. The reaction ran for $24 \mathrm{~h}$ at $40^{\circ} \mathrm{C}$ and was stopped by exposing the mixture to the air. The polymer was dissolved in methanol and precipitated twice in a chloroform-diethyl ether mixture, then dried under vacuum. ${ }^{1} \mathrm{H}-\mathrm{NMR}(300 \mathrm{MHz}$, DMSO-d $\left.\mathrm{d}_{6}, \mathrm{ppm}\right): 4.58-4.50\left(2 \mathrm{H},-\mathrm{O}-\mathrm{CH}_{2}-\right), 4.21-4.08\left(2 \mathrm{H},-\mathrm{CH}_{2}-\mathrm{N}^{+}\right), 3.66-3.46\left(3 \mathrm{H},-\mathrm{OCH}_{3}\right)$, $3.42-3.31\left(9 \mathrm{H},-\mathrm{N}^{+}\left(\mathrm{CH}_{3}\right)_{3}\right), 2.09-1.60\left(2 \mathrm{H},-\mathrm{CH}_{2}-\right), 1.40-0.46\left(3 \mathrm{H},-\mathrm{CH}_{3}\right)$.

\subsection{Anion Exchange Reaction in Polymer Matrix (Example for C1)}

The copolymer C1 (28.11 mg, including $0.05 \mathrm{mmol}$ of ionic units) was dissolved in methanol $(1 \mathrm{~mL})$ and mixed with the proper pharmaceutical salt (i.e., NaPAS $(11.70 \mathrm{mg}$, $0.06 \mathrm{mmol}), \mathrm{KCLV}(11.36 \mathrm{mg}, 0.06 \mathrm{mmol})$, NaFUS (29.86 mg, $0.06 \mathrm{mmol})$, or NaPIP $(29.91 \mathrm{mg}, 0.06 \mathrm{mmol})$. The reaction was carried out for $48 \mathrm{~h}$. The ionic conjugates with pharmaceutical anions (PhA) were obtained after drying under reduced pressure.

To analyze the molecular weight and dispersity index of the synthesized chloridecontaining copolymers (insoluble in standard SEC solvents, including THF), the ion exchange of chloride anions with bistriflimide ions was performed. Copolymer C1 ( $3.82 \mathrm{mg}$, including $0.01 \mathrm{mmol}$ of ionic units) was dissolved in methanol, and then, $\operatorname{LiTf}_{2} \mathrm{~N}$ salt 
$(2.16 \mathrm{mg}, 0.01 \mathrm{mmol})$ was added. The polymer with exchanged anions $\left(\mathrm{Tf}_{2} \mathrm{~N}^{-}\right)$was dried under reduced pressure to give the final product.

\subsection{Drug Release of Pharmaceutical Anions}

The conjugate with pharmaceutical anions $(1.0 \mathrm{mg})$ was dissolved in $1 \mathrm{~mL}$ of phosphate buffered saline (PBS) aqueous solution $(\mathrm{pH}=7.4)$. Then, $1 \mathrm{~mL}$ of polymer solution was placed into a dialysis membrane bag $(\mathrm{MWCO}=3.5 \mathrm{kDa})$ and put into a glass vial filled with $45 \mathrm{~mL}$ PBS. Then, the solution was stirred at $37{ }^{\circ} \mathrm{C}$ for $48 \mathrm{~h}$. During the drug release, buffer samples $(2.5 \mathrm{~mL})$ were collected at consistent time intervals and analyzed on a UV-Vis spectrophotometer. The absorbance of PAS, CLV, FUS, or PIP was measured at 261, 258, 256, or $260 \mathrm{~nm}$, respectively. The quantitative content of the drug in PBS was calculated based on the prepared calibration curve and appointed absorbance maximum wavelengths for the anions with antibacterial activity.

\section{Conclusions}

Several choline-based copolymers were synthesized by ATRP with different content of ionic units (i.e., $25 \%, 50 \%$, and $75 \%$ ), with the ability for self-assembly at CMC below $0.08 \mathrm{mg} / \mathrm{mL}$. The presence of trimethylammonium groups and chloride anions in the main polymer chain was convenient for introducing various pharmaceutical anions with antibacterial properties via an exchange reaction. The resulting conjugates, which act as nanocarriers of ionic drugs, could be applied as oral medicines, owing to their suitable particle sizes (19-306 nm). The conjugated drugs did not exhibit significantly different levels of hydrophilicity in comparison with their chloride matrices, which was confirmed by the wettability of the polymer films evaluated by WCA (the maximum increment was $25^{\circ}$ ). The developed systems were capable of effectively carrying PAS, CLV, and PIP anions, with contents of 59-82\%, 66-95\%, and 43-47\%, respectively. During the release process, PAS anions were removed by phosphate ions from the polymer systems in the largest amounts $(33-46 \% ; 3-6 \mu \mathrm{g} / \mathrm{mL})$. The specific attractive force of CLV and PIP anions to the polymer matrix likely inhibited the release of the drug, and they were replaced at $\sim 10 \%$. The low content of FUS anions induced significant release (21-66\%). The designed ionic conjugates carrying pharmaceutical anions with antibacterial activity may represent interesting systems with potential applications for lung and respiratory treatment, especially because of their physicochemical characteristics and preliminary drug delivery results.

Supplementary Materials: The following are available online at https:/ / www.mdpi.com/1422-006 $7 / 22 / 1 / 284 / s 1$.

Author Contributions: K.N.: data curation, formal analysis, funding acquisition, investigation, project administration, and writing - original draft; D.N.: conceptualization, methodology, project administration, writing - review and editing, and supervision. All authors have read and agreed to the published version of the manuscript.

Funding: This research was funded by the Polish Budget Funds for Scientific Research in 2020 as core funding for R\&D activities in the Silesian University of Technology-funding for young scientists, grant number 04/040/BKM20/0131, and by the National Science Center under the OPUS grant number 2017/27/B/ST5/00960.

Institutional Review Board Statement: Not applicable.

Informed Consent Statement: Not applicable.

Data Availability Statement: Not applicable.

Conflicts of Interest: The authors declare no conflict of interest. 


\begin{tabular}{|c|c|}
\hline Abbreviatior & \\
\hline ATRP & Atom transfer radical polymerization \\
\hline CLV & Clavulanate \\
\hline CMC & Critical micelle concentration \\
\hline DC & Drug content \\
\hline DDS & Drug delivery system \\
\hline DLS & Dynamic light scattering \\
\hline DMSO- $\mathrm{d}_{6}$ & Deuterated dimethyl sulfoxide \\
\hline $\mathrm{EBiB}$ & Ethyl 2-bromoisobutyrate \\
\hline FUS & Fusidate \\
\hline IFT & Interfacial tension \\
\hline $\operatorname{LiTf}_{2} \mathrm{~N}$ & Bis(trifluoromethane)sulfonimide lithium salt \\
\hline MMA & Methyl methacrylate \\
\hline NMR & Nuclear magnetic resonance \\
\hline PAS & $p$-Aminosalicylate \\
\hline PBS & Phosphate buffered saline \\
\hline PDI & Polydispersity index \\
\hline $\mathrm{PhA}$ & Pharmaceutical anion \\
\hline PIL & Poly(ionic liquid) \\
\hline $\mathrm{PIP}^{-}$ & Piperacillin \\
\hline PMDETA & $N, N, N^{\prime}, N^{\prime \prime}, N^{\prime \prime}$-pentamethyldiethylenetriamine \\
\hline SEC & Size exclusion chromatography \\
\hline THF & Tetrahydrofuran \\
\hline TMAMA/Cl & [2-(methacryloyloxy)ethyl]trimethylammonium chloride \\
\hline TMS & Tetramethylsilane \\
\hline UV-Vis & Ultraviolet-visible light spectroscopy \\
\hline WCA & Water contact angle \\
\hline
\end{tabular}

\section{References}

1. Deshpande, A.; Rhodes, C.; Shah, N.; Malick, A. Controlled-Release Drug Delivery Systems for Prolonged Gastric Residence: An Overview. Drug Dev. Ind. Pharm. 1996, 22, 531-539. [CrossRef]

2. Gupta, P.; Vermani, K.; Garg, S. Hydrogels: From controlled release to pH-responsive drug delivery. Drug Discov. Today 2002, 7, 569-579. [CrossRef]

3. Liechty, W.; Kryscio, D.; Slaughter, B.; Peppas, N. Polymers for Drug Delivery Systems. Annu. Rev. Chem. Biomol. Eng. 2010, 1, 149-173. [CrossRef]

4. Deb, P.; Kokaz, S.; Abed, S.; Paradkar, A.; Tekade, R. Pharmaceutical and Biomedical Applications of Polymers. In Advances in Pharmaceutical Product Development and Research, Basic Fundamentals of Drug Delivery; Tekade, R.K., Ed.; Academic Press: Cambridge, MA, USA, 2019; pp. 203-267.

5. Li, H.; Wu, C.; Xia, M.; Zhao, H.; Zhao, M.; Hou, J.; Li, R.; Wei, L.; Zhang, L. Targeted and controlled drug delivery using a temperature and ultra-violet responsive liposome with excellent breast cancer suppressing ability. RSC Adv. 2015, 5, 27630-27639. [CrossRef]

6. Langer, R.; Peppas, N. Chemical and Physical Structure of Polymers as Carriers for Controlled Release of Bioactive Agents, a Review. JMS Rev. Macromol. Chem. Phys. 1983, 23, 61-126. [CrossRef]

7. Lee, J.; Yeo, Y. Controlled Drug Release from Pharmaceutical Nanocarriers. Chem. Eng. Sci. 2015, 125, 75-84. [CrossRef]

8. Zhu, C.; Song, X.; Zhou, W.; Wen, Y.; Wang, X. An efficient cell-targeting and intracellular controlled-release drug delivery system based on MSN-PEM-aptamer conjugates. J. Mater. Chem. 2009, 19, 7765-7770. [CrossRef]

9. Neugebauer, D.; Mielańczyk, A.; Bielas, R.; Odrobińska, J.; Kupczak, M.; Niesyto, K. Ionic Polymethacrylate Based Delivery Systems: Effect of Carrier Topology and Drug Loading. Pharmaceutics 2019, 11, 337. [CrossRef]

10. Odrobińska, J.; Niesyto, K.; Erfurt, K.; Siewniak, A.; Mielańczyk, A.; Neugebauer, D. Retinol-Containing Graft Copolymers for Delivery of Skin-Curing Agents. Pharmaceutics 2019, 11, 378.

11. Kohay, H.; Can Sarisozen, C.; Sawant, R.; Jhaveri, A.; Torchilin, V.; Mishael, Y. PEG-PE/Clay Composite Carriers for Doxorubicin: Effect of Composite Structure on Release, Cell Interaction and Cytotoxicity. Acta Biomater. 2017, 55, 443-454. [CrossRef]

12. Qing, G.; Li, M.; Deng, L.; Lv, Z.; Ding, P.; Sun, T. Smart Drug Release Systems Based on Stimuli-Responsive Polymers. Mini Rev. Med. Chem. 2012, 12, 1-12. [CrossRef]

13. Choi, S.; Zhang, Y.; Xia, Y. A Temperature-Sensitive Drug Release System Based on Phase-Change materials. Angew. Chem. Int. Ed. 2010, 49, 7904-7908. [CrossRef] [PubMed]

14. Zhang, X.; Zhuo, R.; Cui, J.; Zhang, J. A novel thermo-responsive drug delivery system with positive controlled release. Int. J. Pharm. 2002, 235, 43-50. [CrossRef] 
15. Garcia, M.C. Ionic-strength-responsive polymers for drug delivery applications. In Stimuli Responsive Polymeric Nanocarriers for Drug Delivery Applications; Makhlouf, A.S., Ed.; Elsevier: Amsterdam, The Netherlands, 2018; pp. 393-409.

16. Tang, H.; Zhao, W.; Yu, J.; Li, Y.; Zhao, C. Recent Development of pH-Responsive Polymers for Cancer Nanomedicine. Molecules 2019, 24, 4. [CrossRef]

17. Abdollahi, A.; Roghani-Mamaqani, H.; Razavi, B.; Salami-Kalajahi, M. The light-controlling of temperature-responsivity in stimuli-responsive polymers. Polym. Chem. 2019, 10, 5686-5720. [CrossRef]

18. Anand, V.; Kandarapu, R.; Garg, S. Ion-exchange resins: Carrying drug delivery forward. Drug Discov. Today 2001, 6, 905-914. [CrossRef]

19. Ekladious, I.; Colson, Y.; Grinstaff, M. Polymer-drug conjugate therapeutics: Advances, insights and prospects. Nat. Rev. Drug Discov. 2019, 18, 273-294. [CrossRef]

20. Kumar, L.; Verma, S.; Vaidya, B.; Mehra, N. Nanocarrier-Assisted Antimicrobial Therapy Against Intracellular Pathogens. In Nanostructures for Antimicrobial Therapy; Ficai, A., Grumezescu, A.M., Eds.; Elsevier: Amsterdam, The Netherlands, 2017; pp. 293-324.

21. Yokoyama, M.; Kwon, G.; Okano, T.; Sakurai, Y.; Seto, T.; Kataoka, K. Preparation of Micelle-Forming Polymer-Drug Conjugates. Bioconjugate Chem. 1992, 3, 295-301. [CrossRef]

22. He, C.; Tang, Z.; Tian, H.; Chen, X. Co-delivery of chemotherapeutics and proteins for synergistic therapy. Adv. Drug Deliv. Rev. 2016, 98, 64-76. [CrossRef]

23. Sun, J.; Chen, Y.; Huang, Y.; Zhao, W.; Liu, Y.; Venkataramanan, R.; Lu, B.; Li, S. Programmable co-delivery of the immune checkpoint inhibitor NLG919 and chemotherapeutic doxorubicin via a redox-responsive immunostimulatory polymeric prodrug carrier. Acta. Pharmacol. Sin. 2017, 38, 823-834. [CrossRef]

24. Larson, N.; Ghandehari, H. Polymeric Conjugates for Drug Delivery. Chem. Mater. 2012, 24, 840-853. [CrossRef] [PubMed]

25. Pasut, G.; Veronese, F. Polymer-drug conjugation, recent achievements and general strategies. Prog. Polym. Sci. 2007, 32, 933-961. [CrossRef]

26. Yu, Y.; Chen, C.-K.; Law, W.-C.; Mok, J.; Zou, J.; Prasad, P.N.; Cheng, C. Well-Defined Degradable Brush Polymer-Drug Conjugates for Sustained Delivery of Paclitaxel. Mol. Pharm. 2013, 10, 867-874. [CrossRef] [PubMed]

27. Mielańczyk, A.; Neugebauer, D. Designing Drug Conjugates Based on Sugar Decorated V-Shape and Star Polymethacrylates: Influence of Composition and Architecture of Polymeric Carrier. Bioconjugate Chem. 2015, 26, 2303-2310. [CrossRef]

28. Araújo, J.; Florindo, C.; Pereiro, A.; Vieira, N.; Matias, A.; Duarte, C.; Marrucho, I. Cholinium-based ionic liquids with pharmaceutically active anions. RSC Adv. 2014, 4, 28126-28132. [CrossRef]

29. Islam, R.; Chowdhury, R.; Wakabayashi, R.; Tahara, Y.; Kamiya, N.; Moniruzzaman, M.; Goto, M. Choline and amino acid based biocompatible ionic liquid mediated transdermal delivery of the sparingly soluble drug acylovir. Int. J. Pharm. 2020, 582, 119335. [CrossRef]

30. Islam, R.; Chowdhury, R.; Wakabayashi, R.; Kamiya, N.; Moniruzzaman, M.; Goto, M. Ionic Liquid-In-Oil Microemulsions Prepared with Biocompatible Choline Carboxylic Acids for Improving the Transdermal Delivery of a Sparingly Soluble Drug. Pharmaceutics 2020, 12, 392. [CrossRef]

31. Tanner, E.; Curreri, A.; Balkaran, J.; Selig-Wober, N.; Yang, A.; Kendig, C.; Fluhr, M.; Kim, N.; Mitragotri, S. Design Principles of Ionic Liquids for Transdermal Drug Delivery. Adv. Mater. 2019, 31, 1901103. [CrossRef]

32. Boethling, R.; Sommer, E.; DiFiore, D. Designing Small Molecules for Biodegradability. Chem. Rev. 2007, 107, 2207-2227. [CrossRef]

33. Jameson, E.; Quareshy, M.; Chem, Y. Methodological considerations for the identification of choline and carnitine-degrading bacteria in the gut. Methods 2018, 149, 42-48. [CrossRef]

34. Iwasaki, Y.; Ishihara, K. Cell membrane-inspired phospholipid polymers for developing medical devices with excellent biointerfaces. Sci. Technol. Adv. Mater. 2012, 13, 064101. [CrossRef] [PubMed]

35. Lewis, A.; Tang, Y.; Brocchini, S.; Choi, J.; Godwin, A. Poly(2-methacryloyloxyethyl phosphorylcholine) for Protein Conjugation. Bioconjugate Chem. 2008, 19, 2144-2155. [CrossRef] [PubMed]

36. Hu, G.; Emrick, T. Functional Choline Phosphate Polymers. J. Am. Chem. Soc. 2016, 138, 1828-1831. [CrossRef] [PubMed]

37. Shiga, T.; Mori, H.; Uemura, K.; Moriuchi, R.; Dohra, H.; Yamawaki-Ogata, A.; Narita, Y.; Saito, A.; Kotsuchibashi, Y. Evaluation of the Bactericidal and Fungicidal Activities of Poly([2-(methacryloyloxy)ethyl]trimethyl Ammonium Chloride)(Poly (METAC))Based Materials. Polymers 2018, 10, 947. [CrossRef] [PubMed]

38. Bielas, R.; Mielańczyk, A.; Siewniak, A.; Neugebauer, D. Trimethylammonium-based polymethacrylate ionic liquids with tunable hydrophilicity and charge distribution as carriers of salicylate anions. ACS Sustain. Chem. Eng. 2016, 4, 4181-4191. [CrossRef]

39. Bielas, R.; Siewniak, A.; Skonieczna, M.; Adamiec, M.; Mielańczyk, Ł.; Neugebauer, D. Choline based polymethacrylate matrix with pharmaceutical cations as co-delivery system for antibacterial and anti-inflammatory combined therapy. J. Mol. Liq. 2019, 285, 114-122. [CrossRef]

40. Bielas, R.; Łukowiec, D.; Neugebauer, D. Drug delivery via anion exchange of salicylate decorating poly(meth)acrylates based on pharmaceutical ionic liquid. New J. Chem. 2017, 21, 12801-12807. [CrossRef]

41. Bielas, R.; Mielańczyk, A.; Skonieczna, M.; Mielańczyk, Ł.; Neugebauer, D. Choline supported poly(ionic liquid) graft copolymers as novel delivery systems of anionic pharmaceuticals for anti-inflammatory and anti-coagulant therapy. Sci. Rep. 2019, 9, 14410. [CrossRef] 
42. Niesyto, K.; Neugebauer, D. Synthesis and Characterization of Ionic Graft Copolymers: Introduction and In Vitro Release of Antibacterial Drug by Anion Exchange. Polymers 2020, 12, 2159. [CrossRef]

43. Hosseinzadeh, F.; Mahkam, M.; Galehassadi, M. Synthesis and characterization of ionic liquid functionalized polymers for drug delivery of an anti-inflammatory drug. Des. Monomers Polym. 2012, 15, 279-388. [CrossRef]

44. Gorbunova, M.; Lemkina, L.; Borisova, I. New guanidine-containing polyelectrolytes as advanced antibacterial materials. Eur. Polym. J. 2018, 105, 426-433. [CrossRef]

45. Li, Y.; Armes, S.; Jin, X.; Zhu, S. Direct Synthesis of Well-Defined Quaternized Homopolymers and Diblock Copolymers via ATRP in Protic Media. Macromolecules 2003, 36, 8268-8275. [CrossRef]

46. Visnevskij, C.; Makuska, R. SARA ATRP in Aqueous Solutions Containing Supplemental Redox Intermediate: Controlled Polymerization of [2- (Methacryloyloxy)ethyl] trimethylammonium Chloride. Macromolecules 2013, 46, 4764-4771. [CrossRef]

47. Danafar, H. Preparation and characterization of PCL-PEG-PCL polymersomes for delivery of clavulanic acid. Cogent. Med. 2016, 3, 1235245. [CrossRef]

48. Morteza, M.; Roya, S.; Hamed, H.; Amir, Z.; Abolfazl, A. Synthesis and evaluation of polymeric micelle containing piperacillin/tazobactam for enhanced antibacterial activity. Drug Deliv. 2019, 26, 1292-1299. [CrossRef] [PubMed]

49. Yang, C.; Plackett, D.; Needham, D.; Burt, H. PLGA and PHBV Microsphere Formulations and Solid-State Characterization: Possible Implications for Local Delivery of Fusidic Acid for the Treatment and Prevention of Orthopaedic Infections. Pharm. Res. 2009, 26, 1644-1656. [CrossRef] 